\title{
Virus Zika en Centroamérica y sus complicaciones
}

\section{Zika virus in Central America and its complications}

Correspondencia Eduardo S. Núñez Solórzano emastersal@gmail.com

Recibido: 07/03/2016

Arbitrado por pares

Aprobado: 20/04/2016

Citar como:

Núnez $E$, Vásquez $M$, BeltránLuque B, Padgett D. Virus Zika en Centroamérica y sus complicaciones. Acta Med Peru. 2016;33(1):42-9

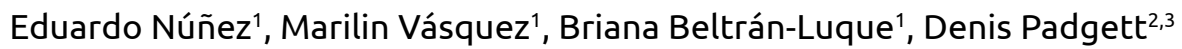 \\ 1 Facultad de Ciencias Médicas, Universidad Nacional Autónoma de Honduras. Tegucigalpa, Honduras. \\ 2 Instituto Hondureño de Seguridad Social. Tegucigalpa, Honduras. \\ 3 Investigación Biomédica, Facultad de Ciencias Médicas, Universidad Nacional Autónoma de Honduras. Tegucigalpa, Honduras.
}

\section{RESUMEN}

El virus Zika (ZIKV) es un arbovirus, aislado por primera vez en Zika Uganda, reportándose el primer caso en humanos en 1954, desde entonces se han descrito casos en África, Asia, Oceanía y en América. Centroamérica ha sido afectada, por cambios climáticos, pobreza y mal saneamiento ambiental. Su transmisión es vectorial y puede tener transmisión perinatal, transfusiones sanguíneas o por semen infectado. Clínicamente se diferencian poco de Dengue y Chikungunya. Sus complicaciones son principalmente a nivel neurológico. Los Gobiernos de las regiones afectadas deberán tener políticas de control del vector, mejoría de viviendas y eliminación de basuras.

Palabras clave:

Virosis; Síndrome de Guillain-Barré; Flavivirus (fuente: DeCS BIREME). 


\section{INTRODUCCIÓN}

El virus Zika (ZIKV) es un arbovirus que pertenece al género Flavivirus, con similitud estructural a los virus del dengue, fiebre amarilla, encefalitis japonesa y virus del Nilo Occidental [1]. Fue aislado por primera vez en el año de 1947 en los bosques de Zika Uganda, reportándose el primer caso en humanos en 1954 en Nigeria [2], desde entonces se han descrito diferentes casos en regiones tropicales de África, Asia, con solo 14 casos documentados en humanos [3]. Su primer brote epidémico de importancia se registró en Micronesia en el año 2007, donde de un total de 185 casos sospechosos se confirmaron 49 y en 2013 en la Polinesia Francesa $[2,4]$, se reportó la mayor epidemia con 28 ooo casos.

En América los primeros casos confirmados se reportaron en la Isla de Pascua (Chile) y en Brasil en 2014 y 2015 respectivamente $[4,5]$. La región centroamericana no ha sido la excepción, dadas las circunstancias climáticas, geográficas, ambientales, socioeconómicas, etc. Según datos oficiales brindados en enero de 2016, se han reportado más de 8500 casos sospechosos, siendo los países mayormente afectados: Honduras, El Salvador y Guatemala, mientras que Costa Rica y Nicaragua son los que menos cantidad de registros presentan [6].

El virus Zika es virus ARN trasmitido por la picadura de mosquitos, principalmente por Aedes aegypti y el Aedes albopictus. Asimismo, se han documentado casos de transmisión perinatal, por transfusiones sanguíneas o por exposición a semen infectado e incluso se ha aislado en saliva por técnicas como reacción en cadena de la polimerasa en tiempo real (PCR TR) $[2,7-9]$. El cuadro clínico es muy semejante al dengue no grave y al chikungunya [10], razón por la cual se subregistran cantidad considerable de casos [6]. No obstante, su importancia radica en las complicaciones asociadas; descritas principalmente a nivel neurológico, que van desde procesos autoinmunes como el Síndrome de Guillain-Barré (SGB); que se asocia en 1 de 1000 casos sintomáticos, hasta malformaciones congénitas como microcefalia $[11,12]$, esto debido a su elevado neurotropismo $[9,13]$. Ocasionando discapacidades de enorme consideración e incluso la muerte en dicha población.

En consecuencia, siendo el Virus Zika actualmente objeto de constante estudio, descubriéndose cada día nuevos hallazgos referentes a dicha enfermedad, se espera que la presente revisión bibliográfica proporcione la información necesaria para las autoridades de salud y comunidad en general de los países regionales, se formen un panorama general y tomen medidas oportunas y precisas encaminadas a la reducción de casos, complicaciones y discapacidades relacionadas a dicha enfermedad.

Para realizar esta revisión se realizó búsqueda bibliográfica durante en los meses de enero a febrero de 2016, en las siguientes bases de datos: PubMed/Medline, SCIELO (Biblioteca Científica Electrónica en Línea), LILACS (Literatura Latinoamericana del Caribe en Ciencias de la Salud), Redalyc (Revistas Científicas de América Latina y el Caribe, España y Portugal) y google académico. Para obtener los datos epidemiológicos de los diferentes países de la región, se contactaron a las autoridades pertinentes de cada una de las Secretarias de Estado en los despachos de Salud, en aquellos países donde no obtuvimos respuesta, la información se recabo a partir de los principales periódicos digitales que circulan en dichos países.

\section{ANTECEDENTES}

El virus Zika con sus siglas (ZIKV) es de tipo ARN y se encontró muy semejante filogenéticamente a los virus del dengue, fiebre chikungunya, fiebre amarilla, encefalitis japonesa y el virus del Nilo Occidental $[14,15]$. Cabe mencionar que ciertos estudios inmunológicos sugieren que el ZIKV mitiga la viremia causada por el virus de la fiebre amarilla en monos, pero no bloquea la transmisión del virus de la fiebre amarilla [5].

La Clasificación Internacional de Enfermedades (CIE), lo cataloga como otras fiebres virales específicas transmitidas por mosquitos ( $\mathrm{ClE} 10 \mathrm{Ag2.8}$ ), recientemente clasificado con CIE 10 Uo6.9; siendo sus principales reservorios: mono, el hombre y los mosquitos, actuando además estos últimos como vectores, quienes principalmente pertenecen al género Aedes: aegypti, albopictus, y también Aedes no presentes en América: africanus, apicoargenteus, furcifer, hensilii, luteocephalus y vitattus $[1,2,4,9,16]$.

Es preciso indicar que el virus Zika ha sido vinculado en otras especies de mosquitos, tales como: Anopheles coustani, Mansonia uniformis y Culex perfuscus. Este último, ha sido aislado en estudios recientes efectuados por investigadores brasileños de la Fundación Oswaldo Cruz, quienes encontraron el virus en las glándulas salivales de dicho mosquito. Sin embargo, su asociación en la transmisión activa hacia las personas es aún objeto de estudio $[9,12,16,17]$.

La infección en seres humanos se confirmó en 1952, mediante análisis serológicos realizados en Uganda y Tanzania, pero fue en 1968 que se logró aislar el virus con muestras provenientes de personas infectadas de Nigeria, donde el $40 \%$ de los pacientes tuvieron anticuerpos comprobados por PRNT $[1,5,14,18]$.

El primer brote de importancia se prolongó durante 13 semanas entre abril y julio de 2007, en la Isla de Yap, Micronesia donde afectó el 73\% de la población [3], y se reportaron 185 casos sospechosos de dicho virus, de los que $49(23 \%)$ se confirmaron laboratorialmente y el $32 \%$ (59) se consideraron probables $[3,4]$.

El virus de Zika fue detectado por primera vez en las Américas en febrero de 2014 por las autoridades de Chile que confirmaron el primer caso en la Isla de Pascua. En mayo de 2015, las autoridades de salud de Brasil confirmaron una transmisión autóctona del patógeno en el noreste del país y hasta octubre de dicho año, el contagio había sido confirmado en 14 estados $[1,18]$. 


\section{EPIDEMIOLOGÍA}

Antes del 2007 apenas se había registrado casos esporádicos de virus Zika a nivel mundial, no obstante, a partir de la última década se han reportado brotes epidémicos en varias islas del pacifico y desde el 2014 brotes autóctonos en distintos países de américa latina $[4,5,11]$. Siendo Brasil uno de los más afectados con una cifra significativa estimada entre 440 000 a 1,3 millones de casos autóctonos reportados hasta Diciembre de $2015[12,16]$. Según diferentes autores, lo anterior puede deberse a los efectos del cambio climático, el calentamiento global y a la mano del hombre, que propician hábitat adecuados para la multiplicación de los vectores, así como también alteran el ciclo natural de la enfermedad como de los propios vectores $[5,10]$.

Actualmente, según datos de la Organización Mundial de la Salud (OMS), más de 21 países de América Latina han confirmado dicha enfermedad [19]. A finales de enero de 2016, en Centroamérica se han registrado más de 8.500 casos, todos los países del istmo centroamericano han sido afectados, siendo los más abatidos Honduras con 5773 registros [20], seguido de El Salvador con 3302 [21], Guatemala con 276 [22], y Panamá con 42 [23]. Por otro lado, Costa Rica y Nicaragua son los que menos reportes presentan con 1 y 3 casos respectivamente $[24,25]$.

Cabe mencionar que una proporción importante de dichos reportes en la mayoría de los países centroamericanos son hechos basados en evidencias clínicas, careciendo de diagnóstico laboratorial confirmatorio, debido probablemente al limitado presupuesto de las Secretarias de Salud. Lo anterior hace posible sospechar que se incurre en una proporción significativa de subregistros, dadas la similitud de su sintomatología con el virus del dengue y Chikungunya $[6,26]$.

\section{PATOGÉNESIS}

La patogénesis del ZIKV actualmente no está muy bien dilucidada, sin embargo estudios realizados sugieren que se inicia al infectar las células dendríticas cerca del sitio de la inoculación de la picadura del mosquito infectado por dicho virus, posteriormente éste se propaga por los ganglios linfáticos y finalmente al torrente sanguíneo, donde su replicación se produce en el citoplasma celular, y se han descrito en esta fase, el hallazgo de antígenos del virus en núcleos de células infectadas $[1,15]$.

Hasta la fecha, ZIKV infeccioso se ha detectado en la sangre humana tan pronto como el día de inicio de la enfermedad y el ácido nucleico viral se ha detectado tan tarde como 11 días después de la aparición. Dicho virus puede ser inhibido artificialmente por compuesto químicos tales como el permanganato de potasio y el éter, así como también por temperaturas mayores a $60^{\circ} \mathrm{C}$ y se neutraliza eficazmente con etanol al 10\% [1].

\section{MANIFESTACIONES CLÍNICAS}

Tras la picadura del mosquito infectado, los síntomas de la enfermedad aparecen generalmente después de un periodo de incubación de 3 a 12 días, dicha infección puede cursar de forma asintomática, o presentarse con una clínica moderada $[2,5,12$ $14,27]$. Su sintomatología es similar a las del virus del dengue y del chikungunya $[2,5,13,27]$ (Tabla 1 ).

Los síntomas se establecen de forma aguda, e incluyen: fiebre de menos de $39^{\circ} \mathrm{C}$, cefalea, mialgia, artralgia, astenia, exantema maculopapular que tiende a comenzar en el rostro y luego se extiende por todo el cuerpo, edema en miembros inferiores, conjuntivitis no purulenta, menos frecuentemente, dolor retro-orbitario, anorexia, vómito, linfadenopatía, diarrea y dolor abdominal. Los síntomas duran entre 4 a 7 días y son autolimitados. Las complicaciones de tipo neurológico y/o autoinmune (Guillain Barré, meningoencefalitis y purpura trombocitopénica) son poco frecuentes 1:1000, siendo identificados inicialmente en un brote epidemiológico en la Polinesia Francesa $[2,5,12-14,27,28]$.

Recientemente en Surinam, en una paciente de 54 años de edad sin aparente historial médico de complicaciones, se asoció el virus Zika a hemorragias subcutáneas y trombocitopenia. De igual manera, ciertos autores han documentado mortalidad en asociación a otras comorbilidades, tal y como se registra en un caso clínico en Colombia, donde una paciente de 15 años de edad con anemia de células falciformes adquirió ZIKV falleciendo sin ningún otro motivo $[29,30]$.

\section{CONDICIONANTES DE RIESGO}

En las principales condicionantes de riesgo asociadas a la transmisión del virus Zika descritas en la actualidad, figuran primeramente la transmisión vectorial a través de la picadura pertenecientes a las especies de Aedes $[7,9,16]$. Centroamérica posee las condiciones climáticas, geográficas y ambientales, propicias para el desarrollo de los vectores, aunado lo anterior con la pobreza y las inadecuadas políticas en materia de salud (observadas en la mayoría de los países de la región), tangibles en la falta de vigilancia ambiental, inapropiada educación en materia de salud, poca salubridad ambiental, mal manejo de fuentes de agua y de desechos sólidos que en suma se convierten en potenciales criaderos para las larvas de los mosquitos transmisores $[10,31]$.

Por otra parte, diferentes autores han expuesto la transmisibilidad de dicho virus por diferentes vías entre ellas la transmisión perinatal, transfusiones sanguíneas o por exposición a semen infectado, demostrándose en esta última condición, presencia macroscópica de hematospermia inducida por la carga viral. Igualmente, ciertos autores han reportado aislamientos de ARN viral en muestras provenientes de leche materna, líquido amniótico, placenta, orina y saliva $[2,8,11,30,32,33]$, aunque no se ha documentado transmisión por estas vías. 
Tabla 1. Comparación de manifestaciones clínicas entre los virus Dengue, Chikungunya y Zika, 2015. Adaptado de Haltead, et al. A partir de la comunicación del Departamento del Servicio de Salud del Estado de Yap, Micronesia.

\begin{tabular}{lccc}
\multicolumn{1}{c}{ Sintomatología } & Dengue & Chikungunya & Zika \\
Fiebre & ++++ & +++ & ++ \\
Mialgias & +++ & +++ & ++ \\
Artralgias & +++ & ++++ & ++ \\
Edema de extremidades & 0 & 0 & ++ \\
Rash maculopapular & ++ & ++ & ++ \\
Dolor retro-orbital & ++ & + & ++ \\
Conjuntivitis & 0 & + & ++ \\
Linfadenopatías & ++ & ++ & + \\
Hepatomegalia & 0 & +++ & 0 \\
Leucopenia & +++ & +++ & 0 \\
Trombocitopenia & +++ & +++ & $0 *$ \\
Hemorragias & + & 0 & $0^{*}$ \\
\hline
\end{tabular}

*Ver bibliografía No.29, donde se describe un caso de ZIKV asociado a trombocitopenia y hemorragias subcutáneas.

\section{Algoritmo Diagnóstico Virus Zika}

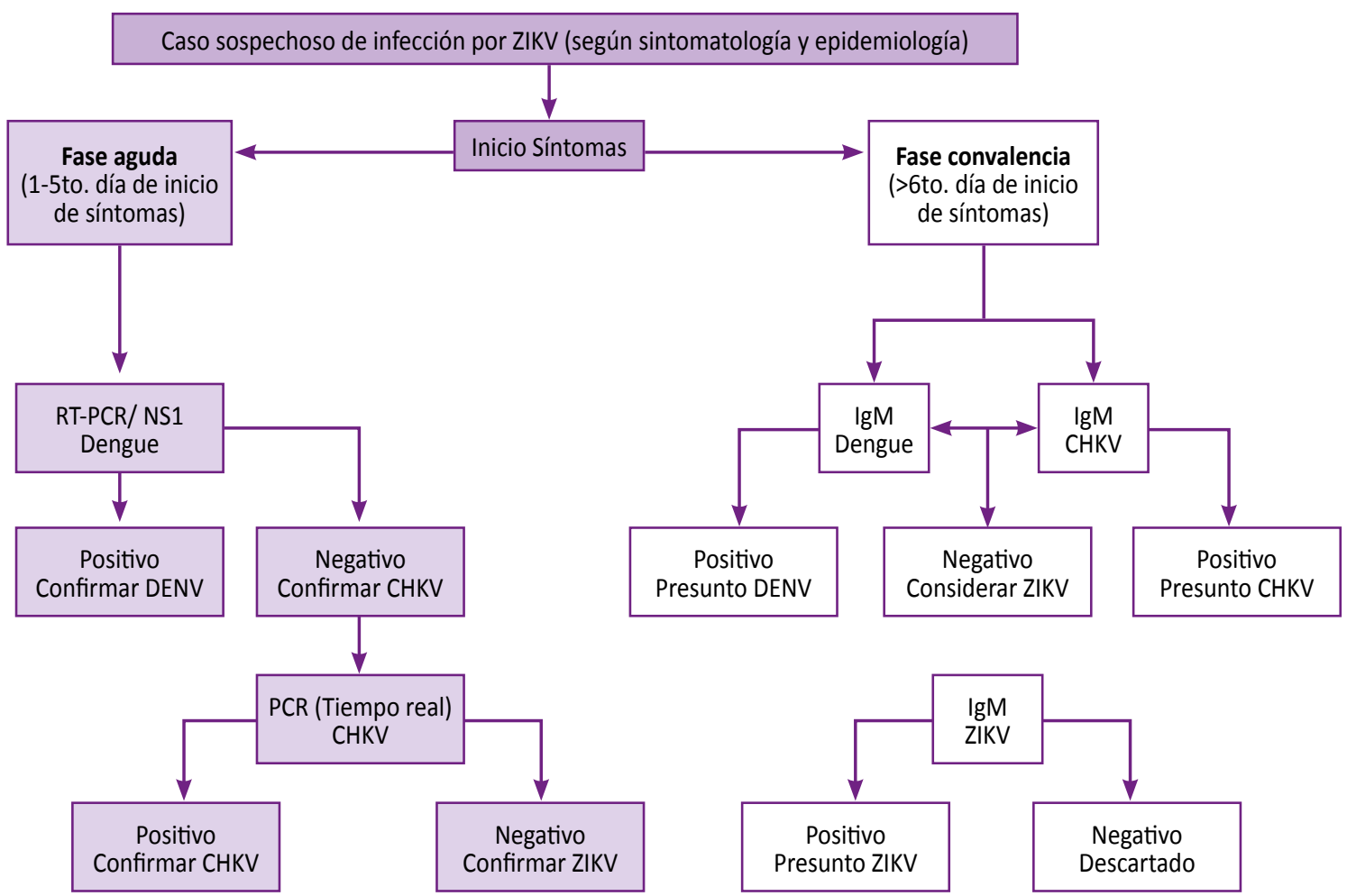

Figura 1. Algoritmo diagnóstico del virus Zika, 2015. Adaptado de Rodríguez-Morales AJ. No era suficiente con Dengue y Chikungunya; llegó también Zika. Archivos de Medicina. 2015. 
Otras condicionantes de riesgo expuestas por ciertos autores son la susceptibilidad de la población y la introducción del virus por viajeros infectados procedentes de áreas endémicas a países donde la epidemia no se ha hecho presente $[11,24]$.

\section{DIAGNÓSTICO}

En la fase aguda (periodo virémico), durante los primeros 5 días tras el establecimiento del cuadro clínico es posible lograr la detección del ARN viral a partir de suero y mediante técnicas moleculares (RT-PCR tiempo real) [14].

Los test serológicos (ELISA o PRTN) específicos para detectar $\lg M \circ \lg G$ frente a dicho virus, son positivos a partir del quinto o sexto día tras el establecimiento del cuadro clínico [14,15], requieren de confirmación con "PRNT" (test de neutralización mediante reducción en placa), siendo positivo al tener un aumento de cuatro veces el título de anticuerpos neutralizantes frente al virus Zika. Se debe tomar en consideración que a veces puede existir reactividad cruzada con otros flavivirus, sobre todo con el dengue, y en menor proporción con fiebre amarilla o virus del Nilo Occidental $[4,27]$.

Asimismo, la OPS ha propuesto algoritmos diagnósticos como herramientas de suma importancia que orientan de forma fidedigna hacia la confirmación de dicha enfermedad (Figura 1). No obstante, cabe mencionar que la mayor limitante actual, es que muchos países de la región aún no cuentan con las pruebas serológicas confiables, ni mucho menos con análisis moleculares para hacer el diagnóstico laboratorial confirmatorio, valiéndose de los hallazgos clínicos sugestivos, pudiendo incurrir en diagnósticos erróneos dadas las similitudes con otras enfermedades vectoriales prevalentes en la región (dengue y chikungunya), ocasionando eventualmente un abordaje inadecuado en la población afectada. Lo anterior probablemente se deba al alto costo económico de dichas pruebas, que limita su uso a nivel público por parte de las autoridades de salud y restringe su acceso a la población en general.

\section{DIAGNÓSTICO DIFERENCIAL}

El virus del Zika comparte similitudes con los virus del Dengue y Chikungunya, tanto filogenéticamente como en su cuadro clínico, por lo cual es importante tratar de diferenciarlos para poder reducir la morbi-mortalidad que produce el Dengue principalmente $[18,27]$. Por ello, hay que resaltar las manifestaciones clínicas menos comunes entre los mencionados virus; sobresale ciertas particularidades presentes en la infección por el virus Zika, entre ellas la conjuntivitis no purulenta, que no está presente en CHIK y mucho menos en el DEN, el edema en extremidades no se observa en DEN ni CHIK, pero sí en Zika. La artralgias son menores y no se presenta artritis como en el chikungunya y el Rash en ZIKA es más temprano y pruriginoso (Tabla 1) [5,34].

\section{COMPLICACIONES}

Las principales complicaciones asociadas al virus Zika se han vinculado con alteraciones neurológicas, de las cuales se menciona la microcefalia como una de las más importantes. Dentro de los casos clínicos estudiados en el primer trimestre de embarazo, se demostró una serie de alteraciones consistentes en: lesión cerebral fetal grave asociada con transmisión vertical, restricción del crecimiento intrauterino acompañada de calcificaciones cerebrales, anormalidades en el flujo arterial cerebral o de ambas arterias umbilicales, oligohidramnios, anhidramnios e incluso muerte fetal. Aislándose este virus en líquido amniótico, membranas fetales, placenta y tejido cerebral fetal $[11,12,28,35-37]$.

Asimismo, son llamativos los diferentes casos reportados de dicho virus con procesos autoinmunes del sistema nervioso como el SGB, que en suma provocan grandes repercusiones en la salud de los afectados tanto a corto como largo plazo e incluso atentan contra la vida de los pacientes. Lo anterior según algunos autores puede deberse a un posible neurotropismo de dicho virus, cierta predisposición de los pacientes y a la elevada virulencia $[11,13,38]$.

En el caso particular de Centroamérica, varios países han registrado un aumento de casos de SGB en personas previamente infectadas por dicho virus [33]. En El Salvador, autoridades del Ministerio de Salud, han reportado un alza de más 46 casos de SGB desde agosto de 2015 hasta enero de 2016, registrando además dos muertes en dicha subpoblación [39]. Caso similar se ha observado en Honduras, donde autoridades sanitarias reportaron dos muertes por SGB en casos sospechosos de Zika, siendo actualmente su asociación motivo de estudio en ambos países [40].

\section{COINFECCIONES}

Diferentes estudios han descrito múltiples casos de coinfecciones entre los diferentes serotipos del virus dengue e incluso entre dengue y chikungunya. Sin embargo, son pocos los casos registrados hasta la fecha de coinfecciones entre dichos virus y el ZIKV, lo anterior posiblemente se deba a las características clínicas similares que comparten dichos virus y a la carencia de pruebas serológicas que confirmen el diagnóstico, probablemente a su elevado costo que restringe su uso a nivel público y a la eventual limitante de acceso de la población en general [41].

No obstante, algunos autores han descrito coinfecciones, entre ellas casos limitados de ZIKV y Dengue, caracterizándose el cuadro clínico por presentar: artralgias, cefalea, dolor retro-orbitario, astenia, mialgias, rash maculopapular, trombocitopenia y leucopenia. Ciertos autores exponen que las coinfecciones alteran la evolución clínica de la enfermedad y al parecer no potencializan la virulencia $[17,41,42]$. 


\section{TRATAMIENTO}

Según recomendaciones de la OMS/OPS, dada que la enfermedad causada por el virus Zika suele ser relativamente leve, su tratamiento se basa en contrarrestar la sintomatología presente, prescribiendo antihistamínicos y antipiréticos (a excepción de las aspirina por aumentar el riesgo de sangrados y Síndrome de Reye en niños menores de 12 años), reposo, ingesta abundante de líquidos $[4,43]$ y vigilancia ambulatoria de signos de alarma ante la posibilidad de fiebre por dengue.

Desafortunadamente no se cuenta hasta la fecha con un tratamiento específico ni con vacunas, razón por la cual algunos Gobiernos del hemisferio, ante el posible riesgo de las complicaciones observadas, han emitido comunicados a su población en general (sobre todo a mujeres en edad reproductiva), donde recomiendan posponer los embarazos en un período determinado [44], dadas las deplorables secuelas congénitas descritas. Entre los países centroamericanos figura El Salvador quien es hasta la fecha el segundo país con más registros de Zika en la región, documentándose a finales de enero de 2016 (SE No.4) 96 casos sospechosos en mujeres embarazadas $[6,21]$.

\section{PREVENCIÓN}

La prevención del virus Zika en la región centroamericana debe de ser una tarea prioritaria y multidisciplinaria, en la que participen todos los sectores de la sociedad, gobiernos, instituciones, centros educativos, población en general, etc. Según recomendaciones de la OMS/OPS, la vigilancia epidemiológica debe de ser un pilar indispensable, y debe de estar orientada a detectar la introducción del virus Zika en un área específica, rastrear la dispersión de la fiebre por virus Zika una vez introducida y vigilar la enfermedad cuando ésta se haya establecido. De igual manera se debe de evaluar la gravedad clínica y el impacto en la salud pública de cada uno de los países e identificar además factores de riesgo asociados a la infección [4,43].

Asimismo, siendo la picadura de los mosquitos la principal forma de transmisión, la OMS/OPS han planteado como medica estratégica la reducción de los mosquitos a través de la eliminación y modificación de los lugares de cría, así como la disminución de los contactos entre los mosquitos y las personas, lo anterior se debe llevar a cabo mediante el uso de repelentes de insectos, ropas (preferiblemente de colores claros) que cubran el cuerpo tanto como sea posible, barreras físicas como mosquiteros o el cierre de puertas y ventanas, uso de mosquiteros de cama, fumigaciones periódicas en barrios, vecindarios y centro públicos, campañas de saneamiento ambiental periódicas, etc. Igualmente, es importante vaciar, limpiar o cubrir los utensilios que pueden acumular agua (cubos, macetas, neumáticos, etc.) eliminando así lugares de cría de mosquitos $[4,43,45]$.

\section{RECOMENDACIONES}

Ante la problemática actual vista en los diferentes países del istmo centroamericano, las principales autoridades de Salud cuya región sea vistoafectada por el aumento significativo de casos del virus Zika, deberán implementar una vigilancia estricta y crear enlaces con los diferentes sectores de la sociedad para que en conjunto logren crear un panorama más claro de cómoproceder frente a este tipo de casos. Asimismo, las autoridades gubernamentales de cada uno de los países afectados, deben crear programas especiales de virus Zika y aumentar los presupuestos de salud, brindar a la población en general la suficiente información acerca de los principales signos y síntomas, población susceptible, métodos diagnósticos, tratamiento correcto, medidas de prevención y complicaciones neurológicas, para evitar la diseminación de nuevos casos, haciendo uso de medios de comunicación escritos, electrónicos, televisivos, radiales, etc.

\section{CONCLUSIÓN}

La región centroamericana se ha visto severamente afectada por el brote epidémico de dicha enfermedad, a finales de enero de 2016 se han reportado un número significativo de casos que desnudan los vulnerables aparatos y políticas de salud pública de cada uno de los países de la región, siendo unos más afectados que otros. Asimismo, la carencia de recursos para realizar pruebas diagnósticas laboratoriales que confirmen dichos casos, es una limitante de gran importancia, ya que propicia probablemente a que una proporción considerable de afectados sean subregistrados, incurriendo posiblemente a que no se brinde un debido manejo y seguimiento a la población afectada. Lo anterior debe ser motivo de mucha preocupación sobretodo en la población vulnerable, ya que se deben de considerar las deplorables secuelas que hasta la fecha se han asociado a dicha enfermedad. Razón por la cual, se estima que los gobiernos deben de realizar una vigilancia epidemiológica oportuna y estricta, fortaleciendo en la población en general la educación en prevención y combate de la enfermedad, creando además programas especiales para el combate de dicha enfermedad aumentando así los presupuestos en materia de salud, incentivar el saneamiento ambiental de forma periódica, involucrando en tales políticas a cada uno de los sectores organizados de la sociedad y de igual manera a las empresas privadas de cada uno de los países.

\section{AGRADECIMIENTOS}

Agradecemos la valiosa colaboración de las autoridades de las Secretarias de Estado en los despachos de Salud de los diferentes países de la región, así como la oportuna información brindada por la Organización Panamericana de Salud, a la Licenciada en periodismo Lucia Zepeda del diario El Heraldo (Tegucigalpa, Honduras) y la valiosa ayuda de Dra. Jackeline Alger (Unidad de Investigación Científica, Facultad de ciencias Médicas, Universidad Nacional Autónoma de Honduras).

Fuente de financiamiento: Autofinanciado.

Conflictos de interés: los autores declaran no tener conflictos de interés con la publicación de este artículo. 


\section{REFERENCIAS BIBLIOGRÁFICAS}

1. Hayes EB. Zika Virus Outside Africa. Emerg Infect Dis. 2009;15(9):1347-50.

2. Valero N. Virus Zika: ¿Otro arbovirus emergente en Venezuela? Invest Clin. 2015;56(3):241-2.

3. Duffy MR, Chen T-H, Hancock WT, Powers AM, Kool JL, Lanciotti RS, et al. Zika virus outbreak on Yap Island, Federated States of Micronesia. N Engl J Med. 2009;360(24):2536-43.

4. Organización Panamericana de Salud (OPS)/ Organización Mundial de la Salud (OMS). Alerta epidemiológica. Infección por virus Zika; mayo 2015 [Internet]. Washington, D.C.: OPS 2016 [citado el 13 de enero 2016]. Disponible en: http://www. paho.org/hq/index.php?option=com_docman\&task=doc_ view\&gid=30077+\&ltemid=999999\&lang=es

5. MattarVS, González TM. Now is the time for the Zika virus. Revista MVZ Córdoba. 2015;20(2):4511-2.

6. Zepeda L. Honduras es el segundo país con más casos de Zika en Centroamérica. Diario El Heraldo. Viernes 22 de enero de 2016. Disponible en: http://www.elheraldo.hn/pais/922468-466/ honduras-es-el-segundo-pa\% $\mathrm{C}_{3} \% \mathrm{ADs}$-con-m $\% \mathrm{C}_{3} \% \mathrm{~A} 1 \mathrm{~s}$-casosde-Zika-en-centroam\%C $3 \%$ Agrica

7. Grard G, Caron M, Mombo IM, Nkoghe D, Ondo SM, Jiolle D, et al. Zika Virus in Gabon (Central Africa) - 2007: A new threat from Aedes albopictus? PLOS Negl Trop Dis. 2014;8(2):e2681.

8. McCarthy M. Zika vírus transmitted by sexual contact in Texas health officials report. BMJ. 2016 Feb 4i352:i720. doi: 10.1136/bmj. i 720 .

9. Brisola-Marcondes C, Ximenes-Melo MF. Zika virus in Brazil and the danger of infestation by Aedes (Stegomyia) mosquitoes. Rev Soc Bras Med Trop. 2016;49(1):4-10.

10. Rivera-García O. Aedes aegypti, virus dengue, Chinkuguya, Zika y el cambio climático. Máxima alerta médica y oficial. REDVET. 2014; 15(10):1-10.

11. Ministerio de Sanidad, Servicios Sociales e Igualdad, Dirección General de Salud Pública, Calidad e Innovación. Evaluación Rápida del Riesgo de transmisión de enfermedad por el virus Zika en España. Madrid: Centro de Coordinación de Alertas y Emergencias Sanitarias; 2015 [citado el 13 enero de 2016]. Disponible en: http://www.msssi.gob.es/profesionales/saludPublica/ccayes/ alertasActual/docs/ERR_Zika_Version-Final_4Dic2015.pdf

12. Mlakar J, Korva M, Tul N, Popović M, Poljšak-Prijatelj M, Mraz $\mathrm{J}$, et al. Zika virus associated with microcephaly. N Engl J Med. 2016;374(10):951-8

13. Brito C. Zika virus: a new chapter in the history of medicine. Acta Med Port. 2015;28(6):679-80.

14. Dirección Vigilancia Sanitaria. Ministerio de Salud El Salvador. Alerta epidemiológica por virus Zika VIGEPES, SIMMOW [Internet]. Bol. Epid. 2015 [citado el 13 enero de 2016];(7):10-16. Disponible en: https://www.salud.gob.sv/archivos/vigi_epide2015/boletines_ epidemilogicos2015/Boletin_epidemiologico_SE192015.pdf.

15. Ministerio de Salud Pública y Asistencia Social, Centro Nacional de Epidemiología. Protocolo de vigilancia epidemiológica enfermedad febril por virus Zika [Internet]. 1ra ed. Guatemala: Centro Nacional de Epidemiología; 2015 [citado el 8 de enero de 2016]. Disponible en: http://epidemiologia.mspas.gob.gt/files/Protocolo\%20Zica. pdf

16. Ayres FC. Identification of Zika virus vectors and implications for control. Lancet. 2016;16:278-9.
17. Carvajal AC, Peña SO, Oletta JF. Infección por Virus Zika (VZIK): Arbovirosis emergente en las Américas. Med Interna (Caracas). 2015;31(1):8-15.

18. Catillo-García S, Bistel-Expósito R, Díaz-Gonzales M, GalindoSantana B, Toledo-Rodríguez I. El virus Zika se propaga en América Latina. BOLIPK. 2015;25(46):362.

19. La OMS advierte que el virus Zika se extenderá por toda América. BBC Mundo. Lunes 25 de enero de 2016. Disponible en: http://www. bbc.com/mundo/noticias/2016/01/160125_salud_Zika_america_ latina_oms_lb

20. República de Honduras, Secretaria de Salud, Dirección de Vigilancia la Salud. Boletín Epidemiológico de Enfermedad Febril por Virus Zika, SE No.5 de 2016. Tegucigalpa: Dirección de Vigilancia la Salud; 2015.

21. Gobierno de El Salvador, Ministerio de Salud, Dirección de Vigilancia Sanitaria. Situación epidemiológica de Zika, SE 01-04 de 2016. San Salvador: Dirección de Vigilancia Sanitaria; 2016.

22. República de Guatemala, Ministerio de Salud Pública y Asistencia Social, Sistema de Información Gerencial de Salud. Casos de morbilidad por Zika, 2015-2da.semana de enero de 2016. Guatemala, Sistema de Información Gerencial de Salud 2016.

23. Piden aplazar embarazos en comarca indígena por Zika. Diario Crítica. Martes 26 de enero de 2016. Disponible en: http://www. critica.com.pa/nacional/piden-aplazar-embarazos-en-comarcaindigena-por-Zika-420118

24. Rojas L. Joven de 25 años es el primer caso de Zika en Costa Rica. Diario Crhoy. Martes 26 de enero de 2016. Disponible en: http:// www.crhoy.com/joven-de-25-anos-es-el-primer-caso-de-Zika-encosta-rica/nacionales/

25. Torres C, Bravo J. Ya son tres casos de Zika en Nicaragua. Diario La Prensa. Jueves 28 de enero de 2016. Disponible en: http:// www.laprensa.com.ni/2016/01/28/nacionales/1976307-llego-Zikanicaragua

26. Zepeda L. Zika podría tener un subregistro de go por ciento. Diario El Heraldo. Jueves 28 de enero de 2016. Disponible en: http:// www.elheraldo.hn/pais/924372-466/Zika-podr\%C3\%ADa-tenerun-subregistro-de-go-por-ciento

27. Rodríguez-MoralesAJ. No era suficiente con Dengue y Chikungunya; llegó también Zika. Arch Med. 2015; 11(2):e3.

28. Brasil $P$, Pereira JP, Gabaglia CR, Damasceno L, Wakimoto $M$, Ribeiro-Nogueira RM, et al. Zika Virus Infection in PregnantWomen in Rio de Janeiro - Preliminary Report. N Engl J Med. 2016 Mar 4 [epub ahead of print].

29. Karimi O, Goorhuis A, Schinkel J, Codrington J, Vreden SG, Vermaat JS, et al. Thrombocytopenia and subcutaneous bleedings in a patient with Zika virus infection. Lancet. 2016;387:939-40.

30. Arzuza-Ortega L, Polo A, Pérez-Tatis G, López-García H, Parra E, Pardo-Herrera $\mathrm{LC}$, et al. Fatal Zika virus infection in girl with sickle cell disease, Colombia. Emerg Infect Dis. 2016;22(5):925-7.

31. Programa de las Naciones Unidad para el Desarrollo (PNUD). Segundo Informe sobre Desarrollo Humano en Centroamérica y Panamá; 2003 [Internet]. San José: PNUD; 2003 [citado el 16 de enero de 2016]. Disponible en: http://www.estadonacion.or.cr/files/ biblioteca_virtual/centroamerica/002/indice_II_ERCA-regiono2. pdf

32. Musso D, Roche C, Robin E, NhanT, Teissier A, Van-MaiC. Potential sexual transmission of Zika Virus. Emerging Infectious Diseases. 2015;21(2):359-61. 
33. Lucey DR, Gostin LO. The emerging Zika pandemic: enhancing preparedness. JAMA. 2016;315(9):865-6.

34. Fauci AS, Morens DM. Zika virus in the Americas- yet another arbovirus threat. N Engl J Med. 2016;374(7):601-4.

35. Heymann DL, Hodgson A, Sall AA, Freedman DO, Staples JE,

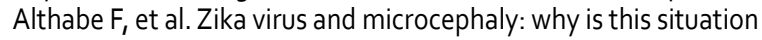
a PHEIC? Lancet. 2016; 387(10020):719-21.

36. Oliveira CS, da Costa-Vasconcelos PF. Microcephaly and Zika virus. J Pediatr (Rio J). 2016;92(2):103-5.

37. Driggers RW, Ho CY, Korhonen EM, Kuivanen S, Jääskeläinen AJ Smura T, et al. Zika virus infection with prolonged maternal viremia and fetal brain abnormalities. N Engl J Med. 2016 Marzo 30 [epub ahead of print].

38. Oliveira-Melo AS, Malinger G, Ximenes R, Szejnfeld PO, Alves Sampaio S, Bispo-de Filippis AM. Zika virus intrauterine infection causes fetal brain abnormality and microcephaly: tip of the iceberg? Ultrasound Obstet Gynecol. 2016; 47(1):6-7.

39. Arias D. Salud sospecha que muerte de dos pacientes con Guillain Barré esté asociada a Zika. Diario La Página. Viernes 8 de enero de 2016. Disponible en: http://www.lapagina.com.sv/ nacionales/113543/2016/01/07/Salud-sospecha-que-muerte-dedos-pacientes-con-Guillain-Barre-este-asociada-a-Zika

40. ACAN-EFE. Honduras investiga una segunda muerte por Zika. Diario La Tribuna. Jueves 28 de enero de 2016. Disponible en: http://www.latribuna.hn/2016/01/28/honduras-investiga-unasegunda-muerte-supuestamente-a-causa-del-Zika/

41. Dupont-Rouzeyrol $M, O^{\prime}$ Connor O, Calvez $E$, Daurès $M$, John $M$, Grangeon JP, et al. Co-infection with Zika and dengue viruses in 2 patients, New Caledonia, 2014. Emerg Infect Dis. 2015;21(2):3812.

42. Pessôa R, Patriota JV, de Souza L, Felix AC, Mamede N, Sanabani SS. Investigation into an outbreak of dengue-like illness in Pernambuco, Brazil, revealed a cocirculation of Zika, Chikungunya, and dengue virus type 1 . Medicine (Baltimore). 2016; 95(12):1-9.

43. Organización Mundial de la Salud (OMS). Enfermedad por el virus Zika [Internet]. Ginebra: OMS; 2016 [citado el 19 de enero de 2016]. Disponible en: http://www.who.int/mediacentre/ factsheets/Zika/es/

44. Redacción central. Ecuador pide a mujeres posponer embarazos por virus Zika. Diario La prensa (ECU). Viernes 22 de enero de 2016. Disponible en: http://www.laprensa.com.ni/2016/01/22/ salud/1974108-ecuador-pide-a-mujeres-postergar-embarazospor-virus-Zika

45. Centro para el Control y la Prevención de Enfermedades. El Virus del Zika. Prevención [Internet]: Atlanta: CDC: c2016 [citado el 31 de enero de 2016]. Disponible en: http://www.cdc.gov/Zika/es/ prevenci\%C3\%B3n/index.html

\title{
Las ediciones anteriores de Acta Médica Peruana están disponibles en:
}

\author{
www.redalyc.org
}

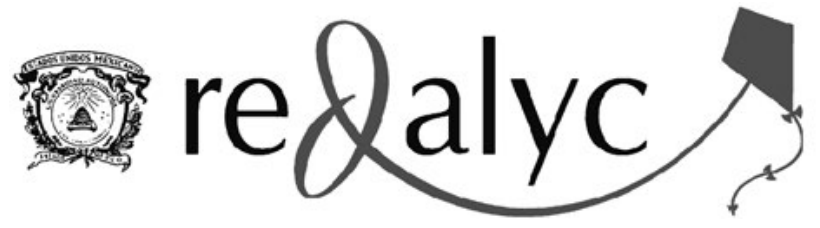

